\title{
Physician Attitudes Toward Homosexuality and HIV: The PATHH-III Survey
}

\author{
Robert Marlin, MD, Ankita Kadakia, MD, Brandon Ethridge, and William C. Mathews, MD ${ }^{1}$
}

\begin{abstract}
Purpose: The aims of this study were (1) to evaluate current physician attitudes toward homosexuality and homosexual, transgender, and HIV-positive individuals and (2) to compare current attitudes of those from prior surveys of the same population, the San Diego County medical community.

Methods: An online survey was conducted during November-December 2017 to assess general attitudes toward homosexuality and medically focused items that addressed homosexual orientation, transgender identity, and HIV. Responses were weighted for nonresponse. Predictors of stigma were assessed using generalized linear models. Trends across three surveys of the same population in 1982, 1999, and 2017 using common items were assessed using unweighted responses.

Results: Of 4418 eligible physicians, 491 (11.1\%) responded (median age 55 years, 38\% female and $8.7 \%$ gay or bisexual). Regarding admission to medical school, $1 \%$ opposed admitting a homosexual applicant, $2 \%$ a transgender applicant, and 5\% an HIV-positive applicant. Regarding consultative referral to a pediatrician, $3 \%$ would discontinue referral to a homosexual pediatrician, $5 \%$ to a transgender pediatrician, and $10 \%$ to an HIV-positive pediatrician. Regarding discomfort treating patients, $7 \%$ reported discomfort treating homosexual patients, $22 \%$ transgender patients, and 13\% HIV-positive patients. Earlier year of graduation from medical school, male gender, and heterosexual orientation were significant predictors of stigma-associated responses. Compared with the results from surveys in 1982 and 1999, the current results suggest substantively less stigma associated with homosexuality and HIV.

Conclusion: There have been substantive declines over a 35-year period in the prevalence of stigmatizing attitudes toward sexual minorities and HIV-positive people among physician respondents in three survey waves of the San Diego County medical community.
\end{abstract}

Keywords: HIV, homosexuality, LGBT, physician attitudes, stigma, transgender

\section{Introduction}

$\mathbf{R}$ ECENT RESEARCH HAS documented important health disparities experienced by LGBT persons in the United States across several health conditions, health behaviors, healthcare access, and utilization characteristics. ${ }^{1,2}$ Stigma has emerged prominently as a potent contributor to at least some of the documented health disparities and may causally relate to disparities both through enactments of stigma by healthcare workers or through consequences of internalized homonegativity. ${ }^{3-6}$ Stigma can have detrimental effects on both healthcare access and quality. ${ }^{7,8}$ Although self-reported attitudes of healthcare providers do not necessarily predict professional or clinical behavior, they are measurable indicators that can inform evaluations of cultural competence to treat patients and to interact with colleagues who are at risk for prejudice.

A recent comparative effectiveness review concluded that the term cultural competence is not well defined for LGBT populations and that most cultural competence intervention studies did not "measure the downstream effect of changing provider beliefs on the care delivered to patients.", Nonetheless, there is theoretical support in Ajzen's theory of planned behavior for the premise that clinician attitudes

\footnotetext{
${ }^{1}$ Department of Medicine, University of California, San Diego, San Diego, California.

${ }^{2}$ San Diego County Medical Society, San Diego, California.

(c) Robert Marlin et al. 2018; Published by Mary Ann Liebert, Inc. This Open Access article is distributed under the terms of the Creative Commons License (http://creativecommons.org/licenses/by/4.0), which permits unrestricted use, distribution, and reproduction in any medium, provided the original work is properly cited.
} 
relate causally to subsequent clinical behavior through the mediation of behavioral intention. ${ }^{10,11}$ Furthermore, there is empirical evidence that stigma-associated attitudes of physicians and health professional students predict behavioral intention to discriminate. ${ }^{12,13}$

Surveys of the membership of the San Diego County Medical Society (SDCMS) regarding attitudes toward homosexuality were conducted in 1982 and 1999, a period that covered the early and established phases of the HIV epidemic in the United States. ${ }^{14,15}$ We conducted a third survey wave of the SDCMS and University of California, San Diego (UCSD), clinical faculty in 2017 to assess further trends in attitudes toward homosexuality and homosexual, transgender, and HIVpositive individuals.

\section{Methods}

\section{Sample}

A 25-item anonymous Internet survey of physician members of the SDCMS and clinical faculty of the UCSD School of Medicine was conducted using the SurveyGizmo platform between November and December 2017 to assess attitudes toward homosexuality, transgender issues, and HIV. The sampling frame included all SDCMS $(n=3337)$ and UCSD $(n=1081)$ physicians who had antecedently given permission to be included in an e-mail registry maintained by the SDCMS, excluding $621(14.7 \%)$ members with no e-mail on file plus an additional $288(6.8 \%)$ who declined e-mail contacts from the SDCMS. A cover letter of invitation to participate signed by the SDCMS President, including a clickable link to the online survey instrument, was e-mailed to all physicians in the sampling frame on November 13, 2017, and was followed by two reminder invitations on November 30 and December 15, 2017.

\section{Measures}

The survey instrument (Appendix 1) ascertained the following demographic characteristics: medical specialty, gender, gender identity, sexual orientation, year of medical school graduation, current practice setting, and SDCMS membership status. The survey included an 8-item 5-category Likert-type attitudinal scale (Heterosexual Attitudes Toward Homosexuality [HATH]-8), composed of 7 items of previously demonstrated high intrinsic consistency reliability from Larsen's 20-item HATH scale plus an additional item concerning attitude toward same-sex marriage. ${ }^{15,16}$ HATH- 8 item responses were averaged with a possible scale range from 1 (most homo-favorable) to 5 (most homo-unfavorable).

The survey then explored medically oriented attitudes of respondents: (1) attitudes toward admission to medical school of homosexual, transgender, and HIV-positive applicants $(1=$ no, $0=$ yes $)$ and (2) behavioral intention to discontinue $(1=$ discontinue) or continue $(0=$ continue) consultative referral upon learning that a consultant physician in each of four specialties (pediatrics, general surgery, psychiatry, and radiation therapy) was homosexual, transgender, or HIV positive. Finally, the survey ascertained affective orientation $(0=$ no negative feelings, $1=$ sometimes uncomfortable, $2=$ often uncomfortable) in treating homosexual, transgender, or HIV-positive patients.

For each target group (homosexual, transgender, and HIV positive), medically oriented attitudes were combined as medical homosexual, transgender, and HIV-stigma indices, respectively, by summing responses across the six medically oriented items (medical school admission [one item], consultative referral [four items], affective orientation toward patients [one item; re-coded: $0=$ no negative feelings, $1=$ sometimes/ often uncomfortable]) for each target group, with possible observable ranges of 0 (most favorable) to 6 (most unfavorable). Scales scores (HATH-8, Medical Homosexual Stigma [MHS], Medical Transgender Stigma, and HIV Stigma [HIVS]) were formed using two metrics: (1) the mean of summed included items and (2) percent of maximum possible (POMP). ${ }^{17}$

Consistent with recent recommendations, we have abandoned the previous terminology incorporating the term "phobia" with reference to unfavorable attitudes and have adopted the term "stigma," itself further categorized as endorsed stigma (on survey items), internalized self-stigma, and expressed (acted out) stigma. ${ }^{18}$ So as to maintain consistency among measures common to all three survey waves, the ambiguous terms "homosexuals" and "homosexuality" were included in the 2017 survey, recognizing that these terms are no longer preferred and lack specificity regarding orientation, identity, and behavior. Likewise, the use of the term "transgender" without further descriptors in the 2017 survey does not capture the complexity of the concept nor of the lived experience.

Finally, because of the availability of data sets from the two preceding SDCMS surveys regarding physician attitudes toward homosexuality, ${ }^{14,15}$ we present a comparison of respondent attitudes using a metric of seven items from the original HATH scale that were used in all three survey waves, HATH-7. For ease of interpretation, HATH-7 scores are presented as POMP scores. In addition, we compare, across the three survey waves, responses to selected common individual items dealing with medical school entry and consultative referral. Because nonrespondent weights were available only for the current (2017) survey wave, the HATH-7 comparisons are based on unweighted scores for all three survey waves (1982, 1999, and 2017). The respondent numbers (response rates) for the 1982 and 1999 survey waves were $1009(42.7 \%)$ and $736(13 \%)$, respectively. ${ }^{14,15}$

\section{Statistical analyses}

Statistical analyses were performed using the survey (svy) suite of functions in Stata 15.1 (StataCorp LLC, College Station, TX). The SDCMS provided selected demographic characteristics (gender, year of medical school graduation, practice setting, medical specialty, and SDCMS membership status) for both respondents and nonrespondents to the survey. These five characteristics were incorporated as inverse probability of response weights, estimated by a logit model of response, to adjust estimates for nonresponse bias. Estimates were further rake calibrated to the marginal totals of the sampling frame. Standard errors were estimated using the jackknife procedure. ${ }^{19}$

Scale intrinsic consistency reliability was estimated as Cronbach's alpha. Spearman's rho was used to estimate correlation among composite measures. Bivariate associations between attitudinal outcome measures and available demographic predictors were analyzed using contingency tables for categorical and ordinal comparisons and analysis of variance for continuous outcomes. Statistically significant results were defined using $p<0.05$ as criterion. Because of 
positive skewness of the composite outcome measures, generalized linear models (GLM) using the gamma distribution with log link, adjusted for survey design characteristics, were fit to evaluate independent effects of characteristics found to be associated with outcomes in bivariate analyses. ${ }^{20}$

Association between selected binary-coded responses dealing with medical school entry, affective orientation about treating patients, and consultant referral, by referent characteristics (student, physician, or patient), was examined using the McNemar matched pair analysis.

\section{Results}

Of 4418 physicians in the sampling frame, 513 (11.6\%) clicked on the survey link embedded in the letter of invitation to participate. Of the 513,491 (11.1\% of 4418) submitted either complete $(n=460)$ or partial $(n=31)$ responses to all items on the survey.

\section{Comparison of participants with nonparticipants}

Table 1 compares the characteristics of those who either clicked (participants) or did not click (nonparticipants) on the invitation letter survey link. Participants were older, graduated from medical school earlier, were more likely to be members of the SDCMS, and were more commonly female and Caucasian. Self-reported gender identity and sexual orientation were available only for survey respondents. One respondent $(0.2 \%)$ identified as transgender ( 2 declining to state) and $41(8.7 \%)$ identified as homosexual or bisexual (8 declining to state).

\section{Survey measures}

Table 2 presents the univariate item and scale distributions. For items with binary response options $(0=$ favorable; $1=$ unfavorable), the reported column means may be interpreted as the proportions of respondents expressing unfavorable attitudes (Table 2). Scale scores are reported both as the mean of summed items and as POMP. The distribution of composite outcome score was highly skewed to the right (positively skewed), with most respondents scoring toward more favorable score ranges (Fig. 1). There was moderate correlation among the composite study measures (Table 2, footnote c).

Table 1. Characteristics of Survey Participants and Nonparticipants

\begin{tabular}{|c|c|c|c|c|}
\hline Characteristic & Nonparticipant & Participant & Total & $\mathrm{p}$ \\
\hline$n(\%)$ & $3905(88.4)$ & $513(11.6)$ & $4418(100.0)$ & \\
\hline Age, median (interquartile interval) & $50(40 ; 61)$ & $55(44 ; 65)$ & $50(40 ; 62)$ & $<0.01$ \\
\hline $\begin{array}{l}\text { Medical school graduation year, median } \\
\text { (interquartile interval) }\end{array}$ & $1996(1983 ; 2007)$ & $1990(1979 ; 2004)$ & $1995(1983 ; 2007)$ & $<0.01$ \\
\hline SDCMS member, $n(\%)$ & & & & 0.02 \\
\hline No & $987(25.3)$ & $105(20.5)$ & $1092(24.7)$ & \\
\hline Yes & $2918(74.7)$ & $408(79.5)$ & $3326(75.3)$ & \\
\hline UCSD affiliation, $n(\%)$ & & & & 0.30 \\
\hline No & $2959(75.8)$ & $378(73.7)$ & $3337(75.5)$ & \\
\hline Yes & $946(24.2)$ & $135(26.3)$ & $1081(24.5)$ & \\
\hline Gender, $n(\%)$ & & & & 0.04 \\
\hline Male & $2472(63.3)$ & $307(59.8)$ & $2779(62.9)$ & \\
\hline Female & $1287(33.0)$ & $194(37.8)$ & $1481(33.5)$ & \\
\hline Undisclosed & $146(3.7)$ & $12(2.3)$ & $158(3.6)$ & \\
\hline Race/ethnicity, $n(\%)$ & & & & $<0.01$ \\
\hline Caucasian & $1235(31.6)$ & $210(40.9)$ & $1445(32.7)$ & \\
\hline Latino/Hispanic & $129(3.3)$ & $21(4.1)$ & $150(3.4)$ & \\
\hline Black & $23(0.6)$ & $1(0.2)$ & $24(0.5)$ & \\
\hline Asian/Native American/Pacific Islander & $305(7.8)$ & $34(6.6)$ & $339(7.7)$ & \\
\hline Other & $21(0.5)$ & $2(0.4)$ & $23(0.5)$ & \\
\hline Undisclosed & $2192(56.1)$ & $245(47.8)$ & $2437(55.2)$ & \\
\hline Specialty groups, $n(\%)$ & & & & 0.04 \\
\hline Anesthesiology & $296(7.6)$ & $37(7.2)$ & $333(7.5)$ & \\
\hline Dermatology & $82(2.1)$ & $8(1.6)$ & $90(2.0)$ & \\
\hline Emergency Medicine & $136(3.5)$ & $22(4.3)$ & $158(3.6)$ & \\
\hline Family Medicine/General Practice & $287(7.3)$ & $37(7.2)$ & $324(7.3)$ & \\
\hline Internal Medicine & $997(25.5)$ & $122(23.8)$ & $1119(25.3)$ & \\
\hline Neurology & $100(2.6)$ & $11(2.1)$ & $111(2.5)$ & \\
\hline Obstetrics and Gynecology & $171(4.4)$ & $28(5.5)$ & $199(4.5)$ & \\
\hline Pathology & $69(1.8)$ & $11(2.1)$ & $80(1.8)$ & \\
\hline Pediatrics & $259(6.6)$ & $50(9.7)$ & $309(7.0)$ & \\
\hline Psychiatry & $163(4.2)$ & $29(5.7)$ & $192(4.3)$ & \\
\hline Radiology & $203(5.2)$ & $28(5.5)$ & $231(5.2)$ & \\
\hline Surgical specialties & $606(15.5)$ & $71(13.8)$ & $677(15.3)$ & \\
\hline Other & $114(2.9)$ & $23(4.5)$ & $137(3.1)$ & \\
\hline Undisclosed & $422(10.8)$ & $36(7.0)$ & $458(10.4)$ & \\
\hline
\end{tabular}

SCDMS, San Diego County Medical Society; UCSD, University of California, San Diego. 
Table 2. Univariate Distribution of Weighted Survey Items and Summary Scales

\begin{tabular}{|c|c|c|c|c|c|}
\hline Item or scale & Mean & $S E$ & Observed range & $\mathrm{N}$ & Possible values \\
\hline \multicolumn{6}{|l|}{ HATH-8 items } \\
\hline Homosexuality is normal & 1.72 & 0.06 & $1-5$ & 455 & $1-5$ \\
\hline Homosexuals working with children & 1.45 & 0.05 & $1-5$ & 459 & $1-5$ \\
\hline Homosexual bars should be closed & 1.25 & 0.03 & $1-3$ & 458 & $1-5$ \\
\hline Homosexuals and social equality & 1.32 & 0.03 & $1-5$ & 458 & $1-5$ \\
\hline Homosexuals and equal opportunity employment & 1.20 & 0.02 & $1-3$ & 459 & $1-5$ \\
\hline No reason to restrict where homosexuals work & 1.29 & 0.03 & $1-5$ & 460 & $1-5$ \\
\hline Bar homosexuals from teaching profession & 1.24 & 0.03 & $1-5$ & 457 & $1-5$ \\
\hline Homosexuals should be allowed to marry & 1.61 & 0.06 & $1-5$ & 459 & $1-5$ \\
\hline \multicolumn{6}{|l|}{ Admission to medical school } \\
\hline Highly qualified homosexual applicant & 0.01 & 0.00 & $0-1$ & 455 & $0-1$ \\
\hline Highly qualified transgender applicant & 0.02 & 0.01 & $0-1$ & 456 & $0-1$ \\
\hline Highly qualified HIV-positive applicant & 0.05 & 0.01 & $0-1$ & 457 & $0-1$ \\
\hline \multicolumn{6}{|l|}{ Referral to a homosexual colleague who is a } \\
\hline Pediatrician & 0.03 & 0.01 & $0-1$ & 458 & $0-1$ \\
\hline General Surgeon & 0.00 & 0.00 & $0-1$ & 455 & $0-1$ \\
\hline Psychiatrist & 0.02 & 0.01 & $0-1$ & 456 & $0-1$ \\
\hline Radiation Oncologist & 0.00 & 0.00 & $0-1$ & 452 & $0-1$ \\
\hline \multicolumn{6}{|l|}{ Referral to a transgender colleague who is a } \\
\hline Pediatrician & 0.05 & 0.01 & $0-1$ & 455 & $0-1$ \\
\hline General Surgeon & 0.02 & 0.01 & $0-1$ & 453 & $0-1$ \\
\hline Psychiatrist & 0.05 & 0.01 & $0-1$ & 452 & $0-1$ \\
\hline Radiation Oncologist & 0.02 & 0.01 & $0-1$ & 451 & $0-1$ \\
\hline \multicolumn{6}{|l|}{ Referral to an HIV-positive colleague who is a } \\
\hline Pediatrician & 0.10 & 0.01 & $0-1$ & 455 & $0-1$ \\
\hline General Surgeon & 0.25 & 0.02 & $0-1$ & 450 & $0-1$ \\
\hline Psychiatrist & 0.04 & 0.01 & $0-1$ & 456 & $0-1$ \\
\hline Radiation Oncologist & 0.04 & 0.01 & $0-1$ & 454 & $0-1$ \\
\hline \multicolumn{6}{|l|}{ Affective orientation ("feelings about") } \\
\hline Homosexual patients & 0.07 & 0.02 & $0-1$ & 458 & $0-1$ \\
\hline Transgender patients & 0.22 & 0.02 & $0-1$ & 454 & $0-1$ \\
\hline HIV-positive patients & 0.13 & 0.02 & $0-1$ & 458 & $0-1$ \\
\hline \multicolumn{6}{|l|}{ Summary scales $\mathrm{b,c}$} \\
\hline HATH-8 & 1.38 & 0.03 & $1-3.5$ & 460 & $1-5$ \\
\hline HATH-8 POMP & 9.66 & 0.77 & $0-62.5$ & 446 & $0-100$ \\
\hline MHS & 0.14 & 0.04 & $0-6$ & 448 & $0-6$ \\
\hline MHS POMP & 2.35 & 0.63 & $0-100$ & 448 & $0-100$ \\
\hline MTS & 0.37 & 0.05 & $0-6$ & 444 & $0-6$ \\
\hline MTS POMP & 6.23 & 0.88 & $0-100$ & 444 & $0-100$ \\
\hline HIVS & 0.61 & 0.06 & $0-6$ & 447 & $0-6$ \\
\hline HIVS POMP & 10.16 & 1.01 & $0-100$ & 447 & $0-100$ \\
\hline
\end{tabular}

${ }^{a}$ Highest values indicate most unfavorable attitude. Lowest values indicate most favorable attitude.

bIntrinsic consistency reliability of scales (Cronbach's alpha): HATH-8 (0.86), MHS (0.57), MTS (0.69), and HIVS (0.75).

'Spearman's rank correlation between HATH-8 POMP and the three other composite measures was 0.28 (MHS), 0.33 (MTS), and 0.32 (HIVS). Correlation of HIVS with MTS was 0.34 and with MHS was 0.32. Spearman's rho between MTS and MHS was 0.53.

HATH, Heterosexual Attitudes Toward Homosexuality; HIVS, HIV Stigma; MHS, Medical Homosexual Stigma; MTS, Medical Transgender Stigma; POMP, percent of maximum possible; SE, standard error of mean.

\section{Bivariate associations}

Table 3 presents the bivariate associations among the attitudinal outcome scales (POMP transformed) and selected covariates. It should first be noted that mean POMP scores did not exceed $25 \%$ of maximum possible (most unfavorable) for any attitudinal outcome or any covariate comparison. Female respondents endorsed significantly less stigma than male respondents on three of the four outcome scales (HATH-8, MHS, and HIVS). Earlier graduates endorsed significantly more stigma than more recent graduates on HATH-8 and HIVS. Outcome means did not differ by practice setting, specialty, or SDCMS membership, although
HIVS POMP was somewhat higher among SDCMS members than nonmembers (11.2 vs. 6.6, $p=0.052)$. Not unexpectedly, those who identified as homosexual or bisexual, or who declined to state their sexual orientation, endorsed less stigma on all composite outcome measures.

\section{Multivariable analyses}

Table 4 presents the results of gamma GLM of the four composite outcome measures on those covariates found in the bivariate analysis to be associated with the outcomes: gender, year of medical school graduation, and sexual orientation. The effects in Table 4 are exponentiated model 

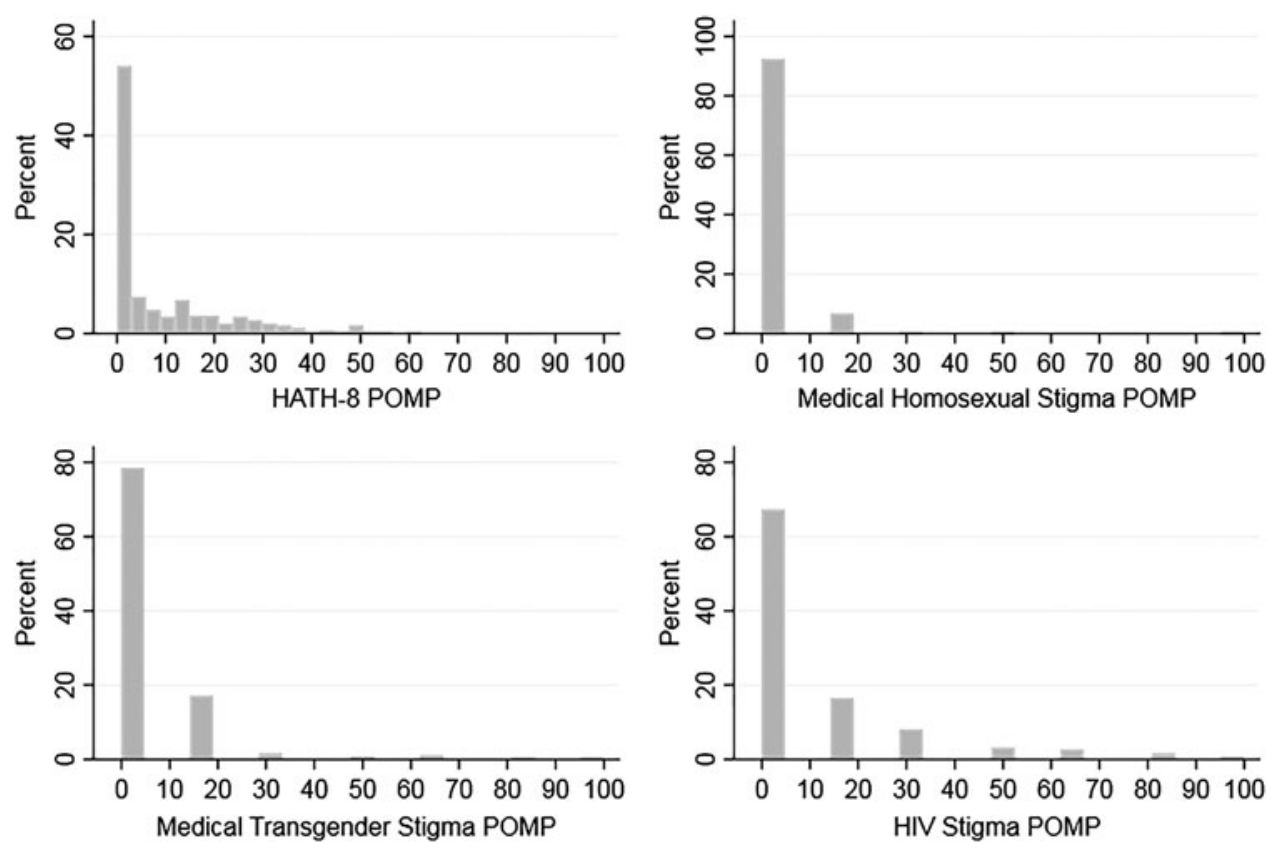

FIG. 1. Distribution of composite outcome measures. coefficients and are interpreted as the ratio of estimated outcome means comparing the index covariate category to the reference category. For example, for HATH-8 POMP, the exponentiated coefficient of 0.45 for female gender represents the estimated ratio of the HATH-8 POMP mean for females to the mean for males. In general, where effects were found, women, more recent graduates, and selfidentifying homosexual or bisexual respondents scored toward the more favorable ranges of the composite outcome measures.

\section{Medically related attitudinal questions}

Regarding associations between opposition to entry to medical school for homosexual, transgender, or HIV-positive individuals, relative to opposition to a homosexual applicant, a transgender applicant was 4.1 times more likely to be opposed (McNemar $p=0.044$ ) and an HIV-positive applicant was 8.5 times as likely to be opposed $(p<0.0001)$. Considering feelings about treating patients, those endorsing being sometimes or often uncomfortable about treating homosexual patients were 3.1 times more likely to have similar feelings about treating transgender patients $(p<0.0001)$ and 1.8 times more likely to have those feelings about treating HIV-positive patients $(p<0.004)$. Finally, regarding referral to a pediatrician, those expressing intent to discontinue referral to a homosexual pediatrician were 1.7 times more likely to discontinue referral to a transgender pediatrician $(p=0.004)$ and 3.5 times as likely to discontinue referral to an HIV-positive pediatrician $(p<0.0001)$.

\section{Comparison with prior two survey waves}

For the unweighted comparison of HATH-7 POMP scores across all three waves of the SDCMS (in 1982, 1999, and 2017), the median (interquartile range [IQR]) scores declined from 42.9 (28.6-64.3) in 1982 to $21.4(7.1-32.1)$ in 1999 and to $0.0(0.0-14.3)$ in 2017 ( $\left.p_{\text {trend }}<0.0001\right)$. Figure 2 presents box plots of HATH-7 POMP scores for the three survey waves, stratified by quartile of year of medical school grad- uation. The figure demonstrates that, although earlier graduates had higher scores (more stigma) than more recent graduates, within the same year of graduation quartile, respondent homosexual stigma decreased from 1982 to 2017. Opposition to entry of a highly qualified homosexual applicant to medical school declined from $30 \%$ in 1982 to $3 \%$ in 1999 and to $0.4 \%$ in 2017. Opposition to medical school entry of a highly qualified asymptomatic HIV-positive applicant with excellent response to antiretroviral therapy declined from $37 \%$ in 1999 to $6 \%$ in 2017.

Regarding consultative referral to specific specialties based on consultant characteristics, intended discontinuation of referral to homosexual pediatricians declined from $46 \%$ in 1982 to $9 \%$ in 1999 and to $2 \%$ in 2017 . The prevalence of intended referral discontinuation to HIV-positive general surgeons declined from 59\% in 1999 to $27 \%$ in 2017 . Regarding predictors of HATH-7 POMP scores across the three survey waves, Table 5 presents the unweighted median (IQR) scores and Kruskal-Wallis $p$ values by sexual orientation, gender, and year of graduation from medical school. Concordant associations were noted for all three covariates across the survey waves except for gender in wave 1 (1982). More recent graduates, self-identified homosexual or bisexual respondents, and women endorsed responses associated with less stigma.

\section{Discussion}

Since the 1982 and 1999 PATHH surveys, there have been dramatic declines in the prevalence of self-reported stigmatizing attitudes toward sexual minorities and HIV-positive persons in the respondents to the SDCMS survey. ${ }^{14,15}$ Consistent predictors of greater sexual orientation stigma across the three survey waves were earlier year of medical school graduation, heterosexual orientation, and male gender. These associations should be understood in the context of significant declines in stigma among respondents with these same characteristics across the three study waves. While the PATHH-I survey noted that certain specialties, such as surgeons, endorsed greater stigma than other 
Table 3. Bivariate Associations of Attitude Scales with Selected Covariates

\begin{tabular}{|c|c|c|c|c|c|c|c|}
\hline Covariate & Scale & Covariate level & Mean & $S E$ & $95 \% C I$ & Test statistic & $\mathrm{p}$ \\
\hline \multirow[t]{13}{*}{ Gender } & & & & & & $F[2,417]$ & \\
\hline & НАТН-8 РОМР & Male & 11.3 & 1.6 & $8.1-14.6$ & 7.19 & 0.0009 \\
\hline & & Female & 4.6 & 0.9 & $2.8-6.4$ & & \\
\hline & & Undisclosed & 18.3 & 9.1 & $0.4-36.2$ & & \\
\hline & MHS POMP & Male & 3.5 & 1.2 & $1.1-5.8$ & 3.36 & 0.0357 \\
\hline & & Female & 0.3 & 0.2 & $0.0-0.7$ & & \\
\hline & & Undisclosed & 1.3 & 3.4 & -5.4 to 8.0 & & \\
\hline & MTS POMP & Male & 7.7 & 1.6 & $4.6-10.9$ & 1.39 & 0.2499 \\
\hline & & Female & 4.0 & 1.3 & $1.5-6.5$ & & \\
\hline & & Undisclosed & 3.6 & 8.8 & -13.7 to 20.8 & & \\
\hline & HIVS POMP & Male & 12.0 & 1.6 & $8.9-15.2$ & 3.37 & 0.0354 \\
\hline & & Female & 6.8 & 1.2 & $4.4-9.1$ & & \\
\hline & & Undisclosed & 7.4 & 17.3 & -26.6 to 41.3 & & \\
\hline \multirow{21}{*}{$\begin{array}{l}\text { Year of medical } \\
\text { school graduation }\end{array}$} & & & & & & $F[4,415]$ & \\
\hline & НАТН-8 РОМР & 1942-1982 & 11.5 & 1.8 & $8.1-15.0$ & 4.53 & 0.0014 \\
\hline & & 1983-1994 & 10.1 & 1.5 & $7.2-13.1$ & & \\
\hline & & $1995-2005$ & 6.8 & 1.5 & $3.8-9.8$ & & \\
\hline & & $2006-2021$ & 4.3 & 1.4 & $1.5-7.0$ & & \\
\hline & & Undisclosed & 23.3 & 7.9 & $7.7-38.8$ & & \\
\hline & MHS POMP & $1942-1982$ & 2.4 & 0.7 & $1.1-3.7$ & 1.97 & 0.0978 \\
\hline & & $1983-1994$ & 1.7 & 0.7 & $0.3-3.0$ & & \\
\hline & & $1995-2005$ & 2.7 & 2.0 & -1.1 to 6.6 & & \\
\hline & & 2006-2021 & 0.6 & 0.4 & -0.2 to 1.3 & & \\
\hline & & Undisclosed & 7.7 & 7.3 & -6.6 to 22.0 & & \\
\hline & MTS POMP & $1942-1982$ & 7.7 & 2.0 & $3.7-11.7$ & 0.71 & 0.5828 \\
\hline & & 1983-1994 & 6.1 & 1.3 & $3.6-8.6$ & & \\
\hline & & $1995-2005$ & 4.3 & 2.0 & $0.3-8.3$ & & \\
\hline & & 2006-2021 & 4.8 & 1.6 & $1.6-7.9$ & & \\
\hline & & Undisclosed & 13.9 & 8.9 & -3.5 to 31.3 & & \\
\hline & HIVS POMP & $1942-1982$ & 20.1 & 2.7 & $14.9-25.4$ & 11.78 & 0.0000 \\
\hline & & $1983-1994$ & 9.0 & 1.5 & $6.0-11.9$ & & \\
\hline & & 1995-2005 & 8.8 & 2.5 & $3.8-13.7$ & & \\
\hline & & $2006-2021$ & 6.1 & 2.4 & $1.4-10.8$ & & \\
\hline & & Undisclosed & 1.0 & 1.4 & -1.7 to 3.8 & & \\
\hline \multirow{17}{*}{ Practice setting } & & & & & & $F[3,416]$ & \\
\hline & НАТН-8 РOMP & Academic medicine & 6.2 & 2.4 & $1.5-10.9$ & 1.07 & 0.3626 \\
\hline & & Integrated medical group & 10.3 & 2.9 & $4.6-16.0$ & & \\
\hline & & Other & 8.5 & 1.6 & $5.5-11.6$ & & \\
\hline & & Private practice & 11.7 & 1.9 & $8.0-15.3$ & & \\
\hline & MHS POMP & Academic medicine & 2.4 & 2.3 & -2.1 to 6.8 & 0.22 & 0.8808 \\
\hline & & Integrated medical group & 2.6 & 1.4 & -0.2 to 5.4 & & \\
\hline & & Other & 1.7 & 0.6 & $0.6-2.8$ & & \\
\hline & & Private practice & 2.7 & 1.4 & -0.1 to 5.5 & & \\
\hline & MTS POMP & Academic medicine & 5.9 & 3.3 & -0.5 to 12.4 & 0.3 & 0.8229 \\
\hline & & Integrated medical group & 6.2 & 2.0 & $2.3-10.1$ & & \\
\hline & & Other & 7.9 & 2.0 & $3.9-11.9$ & & \\
\hline & & Private practice & 5.4 & 1.6 & $2.3-8.5$ & & \\
\hline & HIVS POMP & Academic medicine & 6.5 & 1.8 & $3.0-10.0$ & 2.39 & 0.0681 \\
\hline & & Integrated medical group & 6.6 & 2.5 & $1.7-11.5$ & & \\
\hline & & Other & 12.7 & 2.2 & $8.3-17.2$ & & \\
\hline & & Private practice & 11.2 & 2.2 & $6.8-15.5$ & & \\
\hline \multirow[t]{9}{*}{ SDCMS membership } & & & & & & $F[1,418]$ & \\
\hline & НАТН-8 РОМР & No & 7.1 & 1.7 & $3.7-10.5$ & 1.6 & 0.2066 \\
\hline & & Yes & 10.0 & 1.2 & $7.7-12.4$ & & \\
\hline & MHS POMP & No & 1.0 & 0.5 & $0.1-1.9$ & 2.3 & 0.1304 \\
\hline & & Yes & 2.8 & 1.1 & $0.7-4.8$ & & \\
\hline & MTS POMP & No & 6.2 & 1.9 & $2.4-10.0$ & 0.01 & 0.9432 \\
\hline & & Yes & 6.4 & 1.4 & $3.7-9.1$ & & \\
\hline & HIVS POMP & No & 6.6 & 1.9 & $2.9-10.4$ & 3.81 & 0.0516 \\
\hline & & Yes & 11.2 & 1.4 & $8.5-13.9$ & & \\
\hline
\end{tabular}


TABle 3. (CONTINUED)

\begin{tabular}{|c|c|c|c|c|c|c|c|}
\hline Covariate & Scale & Covariate level & Mean & $S E$ & $95 \% C I$ & Test statistic & $\mathrm{p}$ \\
\hline \multirow[t]{17}{*}{ Specialty } & & & & & & $F[3,416]$ & \\
\hline & \multirow[t]{4}{*}{ НАТН-8 РОМР } & Primary care ${ }^{\mathrm{a}}$ & 8.8 & 1.7 & $5.5-12.0$ & 0.45 & 0.7159 \\
\hline & & Surgical $^{b}$ & 10.7 & 2.0 & $6.7-14.6$ & & \\
\hline & & Psychiatry & 6.1 & 3.4 & -0.6 to 12.9 & & \\
\hline & & Other & 9.4 & 3.0 & $3.5-15.2$ & & \\
\hline & \multirow[t]{4}{*}{ MHS POMP } & Primary care & 2.8 & 1.3 & $0.3-5.3$ & 0.51 & 0.6774 \\
\hline & & Surgical & 1.4 & 0.5 & $0.4-2.3$ & & \\
\hline & & Psychiatry & 1.2 & 1.2 & -1.3 to 3.6 & & \\
\hline & & Other & 3.0 & 2.4 & -1.7 to 7.7 & & \\
\hline & \multirow[t]{4}{*}{ MTS POMP } & Primary care & 6.9 & 1.6 & $3.9-10.0$ & 0.63 & 0.5952 \\
\hline & & Surgical & 4.6 & 1.2 & $2.3-6.9$ & & \\
\hline & & Psychiatry & 6.0 & 2.5 & $1.2-10.8$ & & \\
\hline & & Other & 7.6 & 3.6 & $0.5-14.7$ & & \\
\hline & \multirow[t]{4}{*}{ HIVS POMP } & Primary care & 8.3 & 1.6 & $5.2-11.4$ & 2.09 & 0.1007 \\
\hline & & Surgical & 15.0 & 2.8 & $9.5-20.5$ & & \\
\hline & & Psychiatry & 8.2 & 2.9 & $2.4-14.0$ & & \\
\hline & & Other & 7.4 & 2.0 & $3.5-11.3$ & & \\
\hline \multirow[t]{9}{*}{ Sexual orientation } & \multirow{3}{*}{ НАТН-8 POMP } & & & & & $F[1,418]$ & \\
\hline & & Heterosexual & 10.1 & 1.0 & $8.2-12.0$ & 5.95 & 0.0151 \\
\hline & & Homosexual/bisexual/decline & 2.3 & 3.0 & -3.6 to 8.2 & & \\
\hline & \multirow[t]{2}{*}{ MHS POMP } & Heterosexual & 2.6 & 0.9 & $0.8-4.3$ & 8.38 & 0.0040 \\
\hline & & Homosexual/bisexual/decline & 0.0 & & & & \\
\hline & \multirow[t]{2}{*}{ MTS POMP } & Heterosexual & 6.8 & 1.2 & $4.6-9.1$ & 6.89 & 0.0090 \\
\hline & & Homosexual/bisexual/decline & 1.5 & 2.1 & -2.7 to 5.8 & & \\
\hline & \multirow[t]{2}{*}{ HIVS POMP } & Heterosexual & 10.7 & 1.2 & $8.4-13.0$ & 3.22 & 0.0735 \\
\hline & & Homosexual/bisexual/decline & 4.4 & 3.4 & -2.2 to 11.1 & & \\
\hline
\end{tabular}

aPrimary care includes Family Medicine, General Practice, Internal Medicine, and Pediatrics.

burgical includes General Surgery, Surgical subspecialties, Obstetrics and Gynecology, and Anesthesiology.

CI, confidence interval.

Table 4. Generalized Linear Models of Selected Covariates on Composite Percent of Maximum Possible Outcomes

\begin{tabular}{|c|c|c|c|c|}
\hline Covariate & $H A T H-8,{ }^{\mathrm{a}} \exp (b)^{\mathrm{e}}(S E)$ & $M H S,^{\mathrm{b}} \exp (b)(S E)$ & $M T S,{ }^{\mathrm{c}} \exp (b)(S E)$ & $H I V S,{ }^{\mathrm{d}} \exp (b)(S E)$ \\
\hline \multicolumn{5}{|l|}{ Gender } \\
\hline Male & $1.00()$. & $1.00()$. & $1.00()$. & $1.00()$. \\
\hline Female & $0.45 * * *(0.10)$ & $0.03 * * *(0.02)$ & $0.53 *(0.16)$ & $1.08(0.29)$ \\
\hline Missing/undisclosed & $0.93(0.54)$ & $0.35(0.46)$ & $1.30(1.45)$ & $0.88(0.72)$ \\
\hline \multicolumn{5}{|l|}{ Year of graduation } \\
\hline $1942-$ & $1.00()$. & $1.00()$. & $1.00()$. & $1.00()$. \\
\hline $1983-$ & $0.95(0.18)$ & $2.12(2.12)$ & $0.91(0.31)$ & $0.40 * * *(0.10)$ \\
\hline $1995-$ & $0.62 *(0.14)$ & $0.45(0.34)$ & $0.52(0.26)$ & $0.39 * *(0.12)$ \\
\hline $2006-$ & $0.47 *(0.15)$ & $0.08 * * *(0.06)$ & $0.85(0.35)$ & $0.34 * *(0.13)$ \\
\hline Missing & $1.94 *(0.54)$ & $1.25(0.83)$ & $2.14(0.98)$ & $0.04 * *(0.05)$ \\
\hline Sexual orientation & & Not estimable & & \\
\hline Heterosexual & $1.00()$. & - & $1.00()$. & $1.00()$. \\
\hline Homosexual/bisexual/decline & $0.35 *(0.18)$ & - & $0.18 * *(0.12)$ & $0.33 * *(0.14)$ \\
\hline Observations & 446 & 448 & 444 & 447 \\
\hline
\end{tabular}

(.) indicates that no confidence interval is presented because the indicated category is the reference category.

Because of marked skewness of composite outcomes, models were fit with gamma family distribution and log link.

${ }^{\mathrm{a}}$ HATH-8 POMP covariate $F$ tests: (1) gender $F(2,444)=7.00, p=0.0010$; (2) graduation year $F(4,442)=4.76, p=0.0009$; (3) sexual orientation $F(1,445)=4.25, p=0.0398$.

${ }^{b}$ MHS POMP covariate $F$ tests: $(1)$ gender $F(2,446)=10.26, p<0.00001 ;(2)$ graduation year $F(4,444)=3.64, p=0.0062$. Because all respondents who endorsed being homosexual or bisexual (or declined to state) scored 0 on the MHS POMP outcome, the full generalized linear model failed to converge. Therefore, a reduced model, omitting sexual orientation, was fit for MHS POMP.

${ }^{c}$ MTS POMP covariate $F$ tests: $(1)$ gender $F(2,442)=1.14, p=0.3197$; (2) graduation year $F(4,440)=0.75, p=0.5591$; (3) sexual orientation $F(1,443)=3.08, p=0.0799$.

${ }^{\mathrm{d}}$ HIVS POMP covariate $F$ tests: (1) gender $F(2,445)=0.05, p=0.9494$; (2) graduation year $F(4,443)=5.91, p=0.0001$; (3) sexual orientation $F(1,446)=6.79, p=0.0095$.

${ }^{\mathrm{e}}$ Exponentiated coefficients $[\exp (\mathrm{b})]$ are interpreted as the ratio of the arithmetic means, comparing the index covariate level with the reference level.

$* p<0.05, * * p<0.01, * * * p<0.001$. 
FIG. 2. Distribution of unweighted HATH-7 POMP scores by survey wave (1982, 1999, and 2017), stratified by year of medical school graduation quartile. Test for equality of medians, by year of graduation quartile: $1928-(p<0.0001)$, $1962-(p<0.0001), 1971-$ $(p<0.0001), 1985-$ $(p<0.0001)$. POMP, percent of maximum possible score.

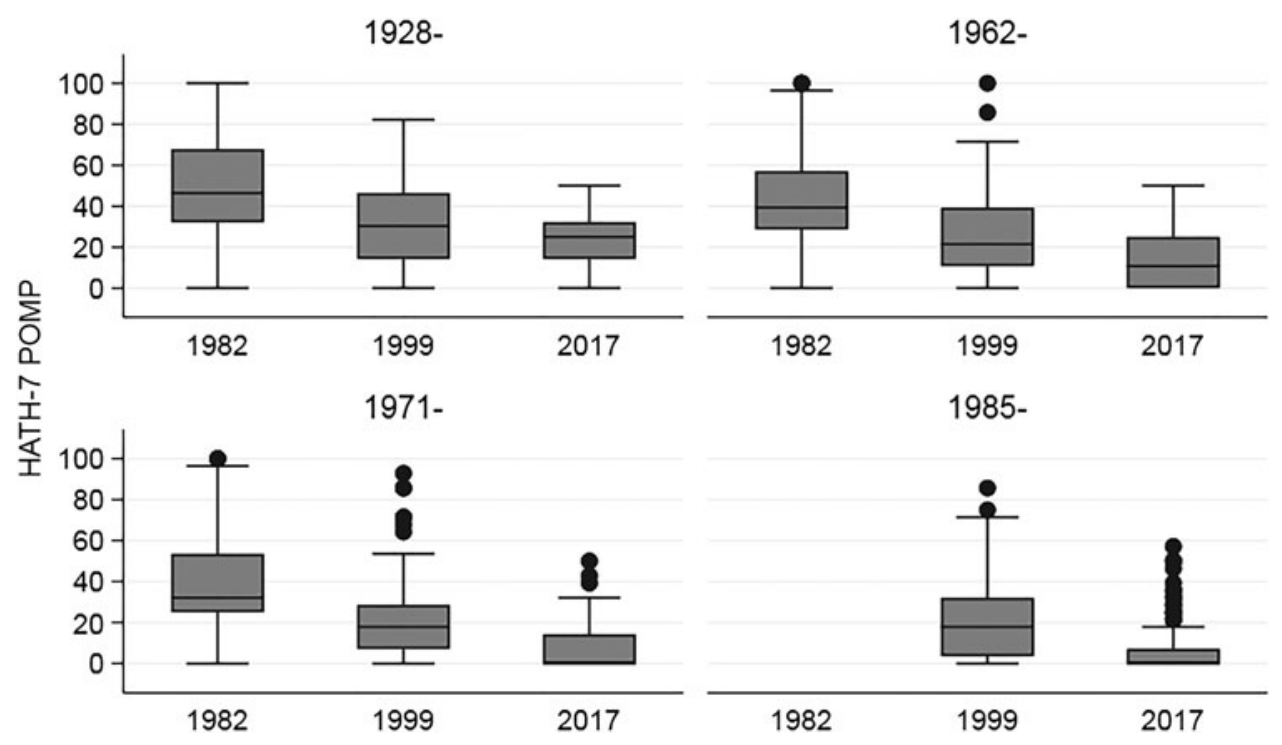

specialties ${ }^{14}$ no difference by specialty was observed in the PATHH-III study. Attitudes toward transgender people were assessed only in the current survey. Although transgender stigma scores were low, they were higher than corresponding gay and lesbian (homosexual) stigma scores but lower than corresponding HIVS scores (Table 2). Matched analysis of association between responses dealing with entry to medical school, referral to pediatricians, and feelings about treating patients revealed that, relative to a gay or lesbian referent, endorsed stigma was amplified 1.7- to 4.1-fold for a transgender referent and 1.8- to 8.5-fold for an HIV-positive referent.

Overall, the results of the current survey, considering prior estimates from 1982 and 1999, mirror broad favorable shifts in Western societal attitudes toward sexual minorities and HIV-positive persons. ${ }^{21-23}$ We are unable to determine whether the more favorable attitudes observed in our most recent survey waves, in comparison to the 1982 survey, are attributable solely to general societal changes or also to con- current enhancements in medical curricula and postgraduate training. ${ }^{24}$ While there are, no doubt, important differences in regional, cultural, and religious attitudes that limit generalizability of the findings, the current results provide some reassurance to physicians and patients who are themselves members of sexual minorities or HIV positive that stigma associated with these characteristics has declined markedly in a major urban medical community in California.

Surprisingly, there have been few similar surveys of physician attitudes toward sexual minorities as patients and colleagues. A New Mexico survey conducted in 1996 used questions from the 1982 San Diego study, allowing for direct comparison. ${ }^{25}$ The acceptability of a gay or lesbian individual being admitted to medical school and the intention to discontinue referral to a gay or lesbian pediatrician were closest to the estimates observed in the San Diego PATHH-II (1999) study (95.7\% vs. $96.8 \%$ and $11 \%$ vs. $10 \%$, respectively). The concordance of survey estimates in the two studies differing in time only by 3 years highlights the potential importance of

Table 5. HATH-7 POMP Scores by Survey Year and Covariate Levels

\begin{tabular}{|c|c|c|c|}
\hline \multirow[b]{2}{*}{ Covariate } & \multicolumn{3}{|c|}{ Survey year } \\
\hline & $\begin{array}{c}1982 \\
\text { Median (IQR) }\end{array}$ & $\begin{array}{c}1999 \\
\text { Median }(I Q R)\end{array}$ & $\begin{array}{c}2017 \\
\text { Median (IQR) }\end{array}$ \\
\hline \multicolumn{4}{|l|}{ Sexual orientation } \\
\hline Heterosexual & - & $21.4(7.1-32.1)$ & $0(0-14.3)$ \\
\hline Homosexual/bisexual/decline & - & $17.9(0-32.1)$ & $0(0-0)$ \\
\hline $\mathrm{KW} p$ value & - & 0.008 & 0.0002 \\
\hline \multicolumn{4}{|l|}{ Gender } \\
\hline Male & $42.9(28.6-64.3)$ & $21.4(7.1-32.1)$ & $3.6(0-17.9)$ \\
\hline Female & $35.7(25-66.1)$ & $14.3(3.6-28.6)$ & $0(0-5.4)$ \\
\hline Missing & $42.9(35.7-71.4)$ & $35.7(7.1-50)$ & $0(0-21.4)$ \\
\hline $\mathrm{KW} p$ value & 0.27 & 0.006 & 0.0001 \\
\hline \multicolumn{4}{|l|}{ Year of graduation } \\
\hline $1928-$ & $46.4(32.1-67.9)$ & $30.4(14.3-46.4)$ & $25(14.3-32.1)$ \\
\hline $1962-$ & $39.3(28.6-57.1)$ & $21.4(10.7-39.3)$ & $10.7(0-25)$ \\
\hline 1971- & $32.1(25-53.6)$ & $17.9(7.1-28.6)$ & $0(0-14.3)$ \\
\hline $1985-$ & - & $17.9(3.6-32.1)$ & $0(0-7.1)$ \\
\hline KW $p$ value & 0.0001 & 0.0001 & 0.0001 \\
\hline
\end{tabular}

$\mathrm{IQR}$, interquartile range; KW, Kruskal-Wallis. 
both regional and temporal factors as determinants of the prevalence and degree of endorsed stigma in similar studies.

To what extent does endorsed stigma in surveys such as the current one predict either internalized self-stigma or expressed stigma by those who endorse stigma-associated responses? This question has been inadequately studied. However, the effect of sexual orientation and/or gender identity stigma is reflected in the reported experiences of LGBT practitioners in the literature. In one national survey, $8 \%$ of LGBT physicians reported that they were denied employment, $2 \%$ denied medical school entry, and $10 \%$ denied patient referral because of their sexual or gender identity. ${ }^{26}$ Perceived sexual and gender minority (SGM) inclusivity has also been shown to have an impact on choice of specialty. SGM physicians have tended to choose specialties that have more SGM persons in them and are perceived to be more inclusive, such as psychiatry, family medicine, pediatrics, and internal medicine. ${ }^{27}$ However, results from the current survey, when compared with the 1982 San Diego results, suggest that differences in specialty-associated sexual orientation stigma may be declining.

The strengths of the current research include the following: (1) it fills a gap in research regarding current attitudes of practicing physicians toward sexual and gender minorities and HIV-positive persons, especially regarding medical contexts; (2) it elucidates important trends and generational effects in attitudes of a major urban California medical community over a 35 -year period; and (3) because of the availability of demographic characteristics of nonrespondents for the 2017 survey wave, nonresponse weighting could be applied to attenuate the effects of nonresponse bias. Future research should explore whether declines in stigma-associated attitudes among clinicians correspond to more favorable healthcare experiences for patients and are also associated with enhanced cultural and medical competencies. Moreover, it would be valuable to explore attitudinal heterogeneity among physicians differing by geographical region and other potentially salient stigmarelated characteristics not assessed in this survey, such as religiosity and political affiliation.

\section{Limitations}

The study has important limitations. First, the click-through response rate was only $11.6 \%$. Although this is similar to the $13 \%$ response rate of the 1999 PATHH-II survey, it is substantively less than the $42.7 \%$ achieved in the 1982 PATHH-I survey and the $54.3 \%$ observed in the 1996 New Mexico survey. ${ }^{25}$ However, the 2017 PATHH-III survey was deployed as an Internet survey, whereas the earlier surveys were mail surveys. Mail surveys have, in some circumstances, been shown to have a four times higher response rate than those deployed online. ${ }^{28}$ The response rate difference has been attributed to potential concerns about confidentiality, ease of internet access, and databases of physician e-mail addresses not being as accurate or up to date as postal addresses. ${ }^{29}$

In addition, our response rate, defined as click-through rate, is somewhat better than the $6.93 \%$ rate reported for surveys of health professionals by Constant Contact as of March $2018 .^{30}$ In addition, online surveys of the SDCMS membership conducted by the SDCMS between 2013 and 2016 had clickthrough rates varying between $1.8 \%$ and $9.9 \%$ (SDCMS, personal communication, November 7, 2017). With such low response rates, the risk for nonresponse bias is substantial. Nonetheless, by employing nonresponse weighting, we believe that the impact of nonresponse bias has been attenuated. Although we were not able to include sexual orientation and gender identity in nonresponse weights, it is reassuring that there were relatively similar proportions of self-reported LGBT respondents in the PATHH-III (8.9\%) and PATHH-II (7\%) surveys, ${ }^{15}$ although both proportions are somewhat higher than the $4.6 \%$ California LGBT population estimated by The Williams Institute. ${ }^{31}$

A second limitation is the generalizability of our findings. As a survey of a single urban California medical community, the results should not be generalized broadly and call for more representative state and national surveys of comparable content.

A third limitation is the knowledge gap that exists regarding the ability of endorsed stigma in surveys to predict both behavioral intention to discriminate and expressed or acted out stigma in patient care and professional relationships.

Fourth, we recognize that our use of the term "transgender" among respondent demographic questions (item 4) does not conform to the currently recommended procedures for ascertaining gender identity. ${ }^{32}$ Finally, our data do not directly address the relationship between stigma-associated attitudes and LGBT care competence, a multidimensional construct amenable to improvement through education, mentorship, and contact with LGBT persons. ${ }^{33-35}$

\section{Conclusions}

We found substantive declines over a 35 -year period in the prevalence of stigmatizing attitudes toward sexual minorities and HIV-positive people among physician respondents in three survey waves of the San Diego County medical community. More recent graduates, self-identified gay or bisexual respondents, and women endorsed responses associated with less stigma. But even among earlier graduates, analysis across all three survey waves showed impressive declines in endorsed stigma. Future research is needed to validate and extend our findings in more varied and representative physician samples.

\section{Acknowledgments}

This work was performed with the support of the Clinical Investigation Core of the UC San Diego Center for AIDS Research (AI036214) and the Pacific AIDS Education and Training Center (HA29292). We thank the SDCMS for invaluable support in conducting this research.

\section{Author Disclosure Statement}

No competing financial interests exist.

\section{References}

1. Ward BW, Dahlhamer JM, Galinsky AM, Joestl SS. Sexual orientation and health among U.S. adults: National Health Interview Survey, 2013. National health statistics reports; no. 77. Hyattsville, MD: National Center for Health Statistics. 2014.

2. Daniel H, Butkus R; Health and Public Policy Committee of American College of Physicians: Lesbian, gay, bisexual, and transgender health disparities: Executive summary of a policy position paper from the American College of Physicians. Ann Intern Med 2015;163:135-137. 
3. Hatzenbuehler ML, Pachankis JE: Stigma and minority stress as social determinants of health among lesbian, gay, bisexual, and transgender youth: Research evidence and clinical implications. Pediatr Clin North Am 2016;63:985-997.

4. Hatzenbuehler ML, Phelan JC, Link BG: Stigma as a fundamental cause of population health inequalities. Am J Public Health 2013;103:813-821.

5. Herek GM: Sexual stigma and sexual prejudice in the United States: A conceptual framework. Nebr Symp Motiv 2009;54: 65-111.

6. Valdiserri RO, Holtgrave DR, Poteat TC, Beyrer C: Unraveling health disparities among sexual and gender minorities: A commentary on the persistent impact of stigma. J Homosex 2018;Jan 3:1-19. [Epub ahead of print]; DOI: 10.1080/ 00918369.2017.1422944.

7. Institute of Medicine (US) Committee on Lesbian, Gay, Bisexual, and Transgender Health Issues and Research Gaps and Opportunities: The Health of Lesbian, Gay, Bisexual, and Transgender People: Building a Foundation for Better Understanding. Washington, DC: National Academies Press, 2011.

8. Jillson IA: Opening closed doors: Improving access to quality health services for LGBT populations. Clin Res Regul Aff 2002;19:153-190.

9. Butler M, McCreedy E, Schwer N, et al.: Improving Cultural Competence to Reduce Health Disparities. Rockville, MD: Agency for Healthcare Research and Quality, 2016.

10. Ajzen I: Attitudes, Personality, and Behavior, 2nd ed. Maidenhead, Berkshire, England and New York: Open University Press, 2005.

11. Armitage CJ, Christian J: Planned Behavior: The Relationship Between Human Thought and Action. New Brunswick, NJ: Transaction Publishers, 2004.

12. Earnshaw VA, Jin H, Wickersham J, et al.: Exploring intentions to discriminate against patients living with HIV/AIDS among future healthcare providers in Malaysia. Trop Med Int Health 2014;19:672-679.

13. Vijay A, Earnshaw VA, Tee YC, et al.: Factors associated with medical doctors' intentions to discriminate against transgender patients in Kuala Lumpur, Malaysia. LGBT Health 2018;5:61-68.

14. Mathews WC, Booth MW, Turner JD, Kessler L: Physicians' attitudes toward homosexuality-survey of a California County Medical Society. West J Med 1986;144:106-110.

15. Smith DM, Mathews WC: Physicians' attitudes toward homosexuality and HIV: Survey of a California Medical Society- revisited (PATHH-II). J Homosex 2007;52:1-9.

16. Larsen KS, Reed M, Hoffman S: Attitudes of heterosexuals toward homosexuality: A Likert-type scale and constructvalidity. J Sex Res 1980;16:245-257.

17. Cohen P, Cohen J, Aiken LS, West SG: The problem of units and the circumstance for POMP. Multivar Behav Res 1999; 34:315-346.

18. Herek GM: A nuanced view of stigma for understanding and addressing sexual and gender minority health disparities. LGBT Health 2016;3:397-399.

19. Center for Population Research in LGBT Health and the Interuniversity Consortium for Political and Social Research (ICPSR): Population Research in Sexual Minority Health (PRISM) Data Archive. Available at www.icpsr.umich.edu/ icpsrweb/content/ICPSR/fenway.html Accessed January 27, 2018.

20. Ng VKY, Cribbie RA: Using the gamma generalized linear model for modeling continuous, skewed and heteroscedastic outcomes in psychology. Curr Psychol 2017;36:225-235.
21. Kaiser Family Foundation: HIV/AIDS at 30: A Public Opinion Perspective. Menlo Park, CA: The Henry J. Kaiser Family Foundation, 2011.

22. Flores AR: National Trends in Public Opinion on LGBT Rights in the United States. Los Angeles, CA: The Williams Institute, UCLA School of Law, 2014.

23. Twenge JM, Carter NT, Keith Campbell W: Time period, generational, and age differences in tolerance for controversial beliefs and lifestyles in the United States, 1972-2012. Soc Forces 2015;94:379-399.

24. Sekoni AO, Gale NK, Manga-Atangana B, et al.: The effects of educational curricula and training on LGBT-specific health issues for healthcare students and professionals: A mixed-method systematic review. J Int AIDS Soc 2017; 20:21624.

25. Ramos MM, Téllez CM, Palley TB, et al.: Attitudes of physicians practicing in New Mexico toward gay men and lesbians in the profession. Acad Med 1998;73:436-438.

26. Eliason MJ, Dibble SL, Robertson PA: Lesbian, gay, bisexual, and transgender (LGBT) physicians' experiences in the workplace. J Homosex 2011;58:1355-1371.

27. Sitkin NA, Pachankis JE: Specialty choice among sexual and gender minorities in medicine: The role of specialty prestige, perceived inclusion, and medical school climate. LGBT Health 2016;3:451-460.

28. Sebo P, Maisonneuve H, Cerutti B, et al.: Rates, delays, and completeness of general practitioners' responses to a postal versus web-based survey: A randomized trial. J Med Internet Res 2017;19:e83.

29. Pit SW, Vo T, Pyakurel S: The effectiveness of recruitment strategies on general practitioner's survey response ratesA systematic review. BMC Med Res Methodol 2014;14:76.

30. Average Industry Rates as of March 2018: Average open, click-through, and bounce rates of Constant Contact customers by industry. 2018. Available at https://knowledgebase .constantcontact.com/guides/KnowledgeBase/5409-averageindustry-rates Accessed May 16, 2018.

31. Same-Sex Couple and LGBT Demographic Data Interactive. Los Angeles, CA: The Williams Institute, UCLA School of Law, 2016. Available at https://williamsinstitute.law.ucla.edu/ visualization/lgbt-stats/?topic=LGBT\#density Accessed February $4,2018$.

32. The GenIUSS Group: Gender-Related Measures Overview. Los Angeles, CA: The Williams Institute, UCLA School of Law, 2013.

33. Earnshaw VA, Jin H, Wickersham JA, et al.: Stigma toward men who have sex with men among future healthcare providers in Malaysia: Would more interpersonal contact reduce prejudice? AIDS Behav 2016;20:98-106.

34. Jann JT, Edmiston EK, Ehrenfeld JM: Important considerations for addressing LGBT health care competency. Am J Public Health 2015;105:e8.

35. Khalili J, Leung LB, Diamant AL: Finding the perfect doctor: Identifying lesbian, gay, bisexual, and transgender-competent physicians. Am J Public Health 2015;105:1114-1119.

Address correspondence to:

Robert Marlin, MD

Department of Medicine University of California, San Diego 200 W. Arbor Drive MC 8824 San Diego, CA 92103-1911

E-mail:rmarlin@ucsd.edu $($ Appendix follows $\rightarrow$ ) 


\section{Appendix 1: PATHH-III Survey}

\section{Introduction}

You are being invited to participate in an anonymous research study entitled Physician's Attitudes Toward LGBT Individuals-PATHH-III Survey. This study is being conducted by Drs. Robert Marlin, Ankita Kadakia, and Christopher Mathews from the University of California, San Diego (UCSD). You were selected to participate in this study because of your membership in California's San Diego County Medical Society and/or because you are UCSD clinical faculty.

The purpose of this research study is to assess provider attitudes toward LGBT issues. We will also assess how these attitudes have changed over time using past surveys. If you agree to take part in this study, you will be asked to complete an online survey. This survey will ask about basic demographic information and your opinions on LGBT issues and will take approximately 5 minutes to complete.

There is no direct benefit to you from this research. The investigators, however, may learn more about attitudes toward LGBT issues in healthcare.

There are some risks associated with survey research including potential violation of confidentiality. Keeping the survey anonymous and collecting only minimal, nonidentifiable demographic data will minimize this risk. We encourage you to take the survey in a private setting to further safeguard anonymity. Research records will be kept confidential to the extent allowed by law and may be reviewed by the UCSD Institutional Review Board.

Your participation in this study is completely voluntary, and you can withdraw at any time by simply exiting the survey. Choosing not to participate or withdrawing will result in no penalty or loss of benefits to which you are entitled.

If you have questions about this project or if you have a research-related problem, you may contact the researcher Robert Marlin at rmarlin@ucsd.edu. If you have any questions concerning your rights as a research subject, you may contact the UCSD Human Research Protections Program Office at 858-246-HRPP (858-2464777).

By clicking "I agree" below you are indicating that you are at least 18 years old, have read this consent form, and agree to participate in this research study. Please print a copy of this page for your records.

(1) Do you agree to participate in this survey?*

() I agree, continue to the survey

() I do not agree, exit the survey after completing demographic questions.

\section{Demographics}

(2) What is your medical specialty*

() Allergy and Immunology

() Anesthesiology
() Colon and Rectal Surgery

() Dermatology

() Emergency Medicine

() Family Medicine

() Internal Medicine

() Medical Genetics and Genomics

() Neurological Surgery

() Plastic Surgery

() Nuclear Medicine

() Obstetrics and Gynecology

() Ophthalmology

() Orthopedic Surgery

() Osteopathic Neuromusculoskeletal Medicine

() Pathology

() Pediatrics

() Physical Medicine and Rehabilitation

() Preventative Medicine

() Psychiatry

() Radiation Oncology

() Radiology

() Surgery

() Thoracic Surgery

() Urology

() Neurology

() General Practice

() Other

(3) What is your gender?*

() Male

() Female

() Nonbinary/third gender

() Decline to state

(4) Do you identify as transgender?*

() Yes

() No

() Decline to state

(5) What is your sexual orientation?*

() Heterosexual

() Homosexual or bisexual

() Decline to state

(6) Year of graduation from medical school:

(7) What is your practice setting?*

() Private Practice

() Academic Medicine

() Retired

() Integrated Medical Group (e.g., Permanente)

() Other 
(8) Are you a member of California's San Diego County Medical Society?*

() Yes

() No

() Unsure

\section{General Attitudes Toward LGBT Issues}

(9) It would be beneficial to society to recognize homosexuality as normal.

() Strongly agree () Agree () Neutral () Disagree

() Strongly disagree

(10) Homosexuals should not be allowed to work with children.

() Strongly agree () Agree () Neutral () Disagree () Strongly disagree

(11) All homosexual bars should be closed down.

() Strongly agree () Agree () Neutral () Disagree () Strongly disagree

(12) Homosexuals should be given social equality.

() Strongly agree () Agree () Neutral () Disagree

() Strongly disagree

(13) Homosexuals should have equal opportunity employment.

() Strongly agree () Agree () Neutral () Disagree

() Strongly disagree

(14) There is no reason to restrict places where homosexuals work.

() Strongly agree () Agree () Neutral () Disagree () Strongly disagree

(15) Homosexuals should be barred from the teaching profession.

() Strongly agree () Agree () Neutral () Disagree

() Strongly disagree

(16) Homosexuals should be allowed to marry.

() Strongly agree () Agree () Neutral () Disagree

() Strongly disagree

\section{Medically Oriented LGBT Questions}

(17) Should a highly qualified homosexual applicant be admitted to medical school?

() Yes

() No

(18) Should a highly qualified transgender applicant be admitted to medical school?

() Yes

() No

(19) Should a highly qualified HIV-positive but asymptomatic applicant, with excellent response to antiretroviral therapy, be admitted to medical school?

() Yes

() No
(20) Suppose you learned that a physician colleague is a homosexual. Would you continue to refer your patients to this physician if he or she worked in any of the following specialties:

\begin{tabular}{lcc}
\hline & $\begin{array}{c}\text { Yes, would } \\
\text { continue to refer }\end{array}$ & $\begin{array}{c}\text { No, would } \\
\text { discontinue referral }\end{array}$ \\
\hline Pediatrics & () & () \\
General Surgery & () & () \\
Psychiatry & () & () \\
Radiation Therapy & () & () \\
\hline
\end{tabular}

(21) Suppose you learned that a physician colleague is a transgender individual. Would you continue to refer your patients to this physician if he or she worked in any of the following specialties:

\begin{tabular}{lcc}
\hline & $\begin{array}{c}\text { Yes, would } \\
\text { continue to refer }\end{array}$ & $\begin{array}{c}\text { No, would } \\
\text { discontinue referral }\end{array}$ \\
\hline Pediatrics & () & () \\
General Surgery & () & () \\
Psychiatry & () & () \\
Radiation Therapy & () & () \\
\hline
\end{tabular}

(22) Suppose you learned that a physician colleague is HIV infected. Would you continue to refer your patients to this physician if he or she worked in any of the following specialties:

\begin{tabular}{lcc}
\hline & $\begin{array}{c}\text { Yes, would } \\
\text { continue to refer }\end{array}$ & $\begin{array}{c}\text { No, would } \\
\text { discontinue referral }\end{array}$ \\
\hline Pediatrics & () & () \\
General Surgery & () & () \\
Psychiatry & () & ( \\
Radiation Therapy & () & () \\
\hline
\end{tabular}

(23) How do you feel about treating homosexual patients?

() No negative feelings

() Sometimes uncomfortable

() Often uncomfortable

(24) How do you feel about treating transgender patients?

() No negative feelings

() Sometimes uncomfortable

() Often uncomfortable

(25) How do you feel about treating HIV-positive patients?
() No negative feelings
() Sometimes uncomfortable
() Often uncomfortable

Thank You!

Thank you for taking our survey. Your response is very important to us. 